\title{
Optimization of perishable goods delivery in supply chains with random demand
}

\author{
Vladimir Anisimov 1,*, Anton Shaban ${ }^{1}$, Evgenii Anisimov ${ }^{2}$, Tatyana Saurenko ${ }^{2}$, and \\ Vladimir Yavorsky ${ }^{3}$ \\ ${ }^{1}$ Peter the Great St. Petersburg Polytechnic University (SPbPU), Graduate School of Business and \\ Management, 29, Polytechnicheskaya, 195251, St. Petersburg, Russia \\ ${ }^{2}$ People's Friendship University of Russia (RUDN University), 6, Miklukho-Maklaya Str., Moscow, \\ Russia \\ ${ }^{3}$ Karaganda State Technical University, Karaganda, Russia
}

\begin{abstract}
The article suggests a model for defining a rational range and volume of supply of perishable goods in their supply chains functioning at the time of random demand. In the verbal formulation, the goal of the model is to determine the range and delivery volumes of perishable goods that maximize profits with restrictions on the funds available for their purchase, storage volumes and weight, as well as on lost profits. The formalized representation of the model is determined by the properties of the supplied perishable goods. If these goods are divisible, then the model is formalized as a linear programming problem. In this case, the rational assortment and volume of goods is determined by solving it, for example, using the simplex method.If the goods under consideration are piece (indivisible), they are formalized in the form of a corresponding integer programming problem. In this case, the rational assortment and volume of goods is determined by solving it, for example, based on the branch and bound method. The peculiarity of the model is that it takes into account the stochastic nature of demand for goods, their limited shelf life, as well as the possibility of storing goods and the availability of funds necessary to purchase the next batch.
\end{abstract}

\section{Introduction}

Creating and providing goods and services to the end consumers is implemented in supply chains. From the object perspective, a supply chain connects organizations that interact in the flows of goods and services from the source of raw materials to the end consumer. Such organizations, in particular, can be manufacturers of products, transport companies, warehouses, wholesale and retail enterprises, etc. [1 - 4]. From the process perspective, a supply chain links material, information and financial flows between the chain participants. The totality of these flows forms the cost of goods and services and, ultimately, provides for consumer demand [5 - 7]. Therefore, organizing supply chains and managing their performance are the most important areas of economic activity. They determine both the profit of chain participants and the degree to which consumer demand is met [8 - 11]. The considered circumstances determine the problem of forming supply chains and managing

* Corresponding author: an-33@yandex.ru 
their performance. The problem becomes especially acute when the range and volumes of supplies of perishable goods are determined in supply chains with random demand [12]. This is caused by the specifics of storage and short shelf life of such goods (see, for example, Figure 1 [13]), as well as high losses both in case of their deficit and surplus.

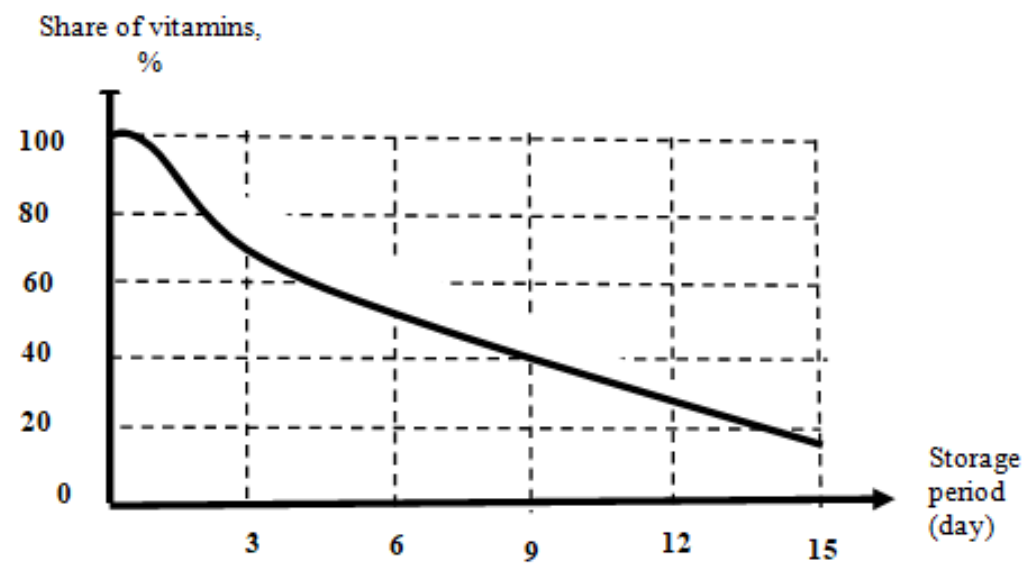

Fig. 1. Dynamics of loss of vitamins in strawberries, depending on the shelf life.

Losses due to deficiency are manifested in lost profit, and losses of surplus are manifested in inability to sell the goods with expired shelf life. Consequently, the solutions in managing perishable goods deliveries at the time of random demand should be based on accounting these losses correctly. Such accounting, in particular, is provided by applying appropriate models. Developing a variant of such a model is the purpose of this paper. Let us consider how the model is built on the example of forming the solutions related to the volume and range of perishable goods supplied to a retailer.

\section{Materials and methods}

In supply chain management, significant attention is paid to the development of methods for the formation of rational (optimal) options for appropriate management decisions that provide competitive advantages to companies participating in the supply chain. These advantages, as a rule, are formed by reducing the time for bringing goods and services to the end consumer, as well as reducing the costs associated with the supply of goods. The formation of solutions that ensure the achievement of these advantages is based on the corresponding models. At the same time, the degree of rationality of management decisions is determined by the adequacy of the models to the real supply process. The peculiarity of the process of supplying perishable goods consists in the randomness of demand for them and is characterized by significant costs of the participants in the supply chain both in the case of a shortage of supplied goods, and in the case of their excess. In this regard, an important problem arises of building a model for optimizing the supply of perishable products in supply chains with random demand, with restrictions on the funds available for the purchase of goods, storage volumes and weight, as well as on lost profits in case of a shortage of goods. Its solution is based on the combination of stochastic and optimization approaches in modeling. At the same time, stochastic approaches ensure the coordination of supply and demand for supplied perishable goods. Optimization approaches implement the choice of assortment and supply volumes of goods that maximize the profits of participants in the supply chain under existing constraints. 


\section{Results}

The logistic supply chain of perishable products is presented in the form of Figure 2 [12].

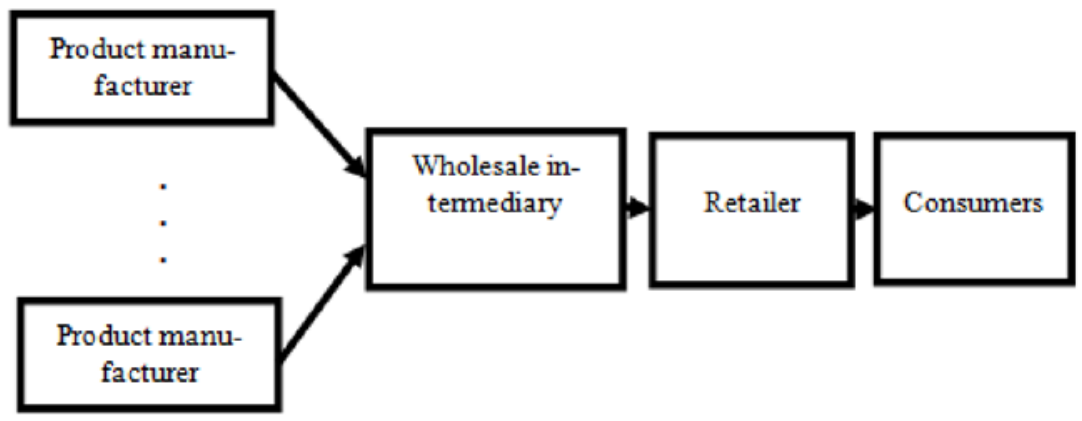

Fig. 2. Logistic supply chain for perishable goods.

To formalize the representation of the process of forming decisions on the assortment and volumes of supply of perishable goods in the chain of Fig. 2 under conditions of random demand, we introduce the notation:

$J$ is the number of types of perishable goods in the range of a retailer;

$T_{j}$ is the shelf life of the $\mathrm{j}$-th type of perishable goods $(\mathrm{j}=1,2, \ldots, \mathrm{J})$;

$T$ is the delivery period of perishable goods;

$W_{j}\left(T_{j}\right)$ is the income of the retailer from the sale of the $\mathrm{j}$-th type of perishable goods over the period of time $T_{j}$;

$c_{j}$ is the retail price of the unit of the $\mathrm{j}$-th type of goods;

$c_{0 j}$ is the wholesale price of the unit of the $\mathrm{j}$-th type of goods;

$y_{j}\left(T_{j}\right)$ is the supply volume of the $\mathrm{j}$-th type of perishable goods over the period $T_{j}$;

$y_{j} *\left(T_{j}\right)$ is the sales volume of the $\mathrm{j}$-th type of perishable goods $(\mathrm{j}=1,2, \ldots, \mathrm{J})$ over the period $\mathrm{T}_{\mathrm{J}}$

$\hat{y}_{j}\left(T_{j}\right)$ is the shortage of the $\mathrm{j}$-th type of goods $(\mathrm{j}=1,2, \ldots, \mathrm{J})$ caused by random demand over the period $\mathrm{T}_{\mathrm{j}}$;

$V_{j}$ is the volume needed to store a unit of the j-th type of goods;

$G_{j}$ is the weight of a unit of the $\mathrm{j}$-th type of goods;

$V^{*}$ is the allowable volume of the stock of perishable goods stored in the warehouse of the retailer;

$G^{*}$ is the allowable weight of the stock of perishable goods stored in the warehouse of the retailer;

$C_{0}$ is the volume of funds the retailer has for wholesale purchase of perishable goods.

Taking into account the above designations, the income of the retailer from the sale of the $\mathrm{j}$-th type of goods over the period of time $\mathrm{T}_{\mathrm{j}}$ is determined by the equation

$$
W_{j}\left(T_{j}\right)=c_{j} y_{j}^{*}\left(T_{j}\right)-c_{0 j} y_{j}^{*}\left(T_{j}\right)-c_{0 j}\left[y_{j}\left(T_{j}\right)-y_{j}^{*}\left(T_{j}\right)\right]=c_{j} y_{j}^{*}\left(T_{j}\right)-c_{0 j} y_{j}\left(T_{j}\right)
$$

Let us assume that all perishable goods (every the $\mathrm{j}$-th $(\mathrm{j}=1,2, \ldots, \mathrm{J})$ type of goods) are delivered to the retailer with frequency $T_{j}$.

In this case, the total volume of goods supplied in one update cycle and their range are formally represented by the vector $Y=\{\mathrm{y} 1, \mathrm{y} 2, \ldots, \mathrm{yJ}\}$, whose components reflect the volume of one consignment of the corresponding type of goods. Then the total income of $W(Y)$ retailer from selling the whole range of perishable goods supplied during one update cycle is determined by the equation 


$$
W(Y)=\sum_{j=1}^{J} W_{j}\left(T_{j}\right)
$$

Demand for each $\mathrm{j}$-th type of goods will be presented in the form of the simplest discrete flow of demand with intensity $\lambda_{j}, j=1,2, \ldots, J$. The reasonability of such a representation follows from the information situation, which is typical for the supply management of the goods under consideration. It involves the fact that we need only information about the average number of demand for each $j$-th $(j=1,2, \ldots, J)$ type of goods in the preceding period of time to form a management decision.

There is no shortage of each $\mathrm{j}$-th type of goods, if the quantity kj of the demanded units of these goods during their supply period $\mathrm{Tj}$ will not exceed the supply volume yj.

Since demand is the simplest flow of requests, the probability $P_{j k_{j}}\left(T_{j}\right)$ that at time $T_{j}$ there will be $\mathrm{kj}$ requests for the $\mathrm{j}$-th type $(\mathrm{j}=1,2, \ldots, \mathrm{J})$ of goods, is determined by Poisson's formula

$$
P_{j k_{j}}\left(T_{j}\right)=\frac{\left(\lambda_{j} T_{j}\right)^{k_{j}}}{k_{j} !} e^{-\left(\lambda_{j} k_{j}\right)}, \quad j=1,2, \ldots, J
$$

where $\left(\lambda_{j} T_{j}\right)$ is the average expected number of requests for the $\mathrm{j}$-th type of goods over the period $T j$.

Given (3), the mathematical expectation $y j *(T j)$ of the sales volume of perishable goods of the $\mathrm{j}$-th type $(\mathrm{j}=1,2, \ldots, \mathrm{J})$ for the period $T j$ is determined by the equation:

$$
y_{j}^{*}\left(T_{j}\right)=\sum_{k_{j}=0}^{y_{j}} k_{j} \frac{\left(\lambda_{j} T_{j}\right)^{k_{j}}}{k_{j} !} e^{-\left(\lambda_{j} k_{j}\right)}, \quad j=1,2, \ldots, J
$$

The mathematical expectation of deficit of the $\mathrm{j}$-th type $(\mathrm{j}=1,2, \ldots, \mathrm{J})$ of goods for the time period $\mathrm{T} j$, is determined by the equation:

$$
\hat{y}_{j}\left(T_{j}\right)=\sum_{k_{j}=0}^{y_{j}} k_{j}\left[1-\frac{\left(\lambda_{j} T_{j}\right)^{k_{j}}}{k_{j} !} e^{-\left(\lambda_{j} k_{j}\right)}\right], \quad j=1,2, \ldots, J
$$

Taking into account (4) and the fact that the supplies of the j-th type of goods are carried out with the frequency $T j$, it follows from (1) that the expected income of the retailer from the sale of the $\mathrm{j}$-th type of goods over the period of one supply is equal to

$$
W_{j}\left(T_{j}\right)=\left(c_{j}-c_{o j}\right) y_{j}^{*}\left(T_{j}\right), \quad j=1,2, \ldots, J
$$

The total revenue of the retailer from the sale of a single batch of the entire range of perishable goods received in the process of one supply is determined by the following equation

$$
W(Y)=\sum_{j=1}^{J} W_{j}\left(T_{j}\right)
$$


Given (5), the lost profit due to a shortage of goods of the $\mathrm{j}$-th type $(\mathrm{j}=1,2, \ldots, \mathrm{J})$ over the time period $T j$, is determined by the following

$$
\hat{W}_{j}\left(T_{j}\right)=\sum_{k_{j}=0}^{y_{j}} c_{j} k_{j}\left[1-\frac{\left(\lambda_{j} T_{j}\right)^{k_{j}}}{k_{j} !} e^{-\left(\lambda_{j} k_{j}\right)}\right], \quad j=1,2, \ldots, J
$$

The total profit lost due to the deficit of the entire range of perishable goods received in the process of one supply is determined by the following equation

$$
\hat{W}(Y)=\sum_{j=1}^{J} \sum_{k_{j}=0}^{y_{j}} c_{j} k_{j}\left[1-\frac{\left(\lambda_{j} T_{j}\right)^{k_{j}}}{k_{j} !} e^{-\left(\lambda_{j} k_{j}\right)}\right]
$$

Taking into account (7), (9) and the introduced designations, the problem of defining a rational range and volumes of perishable goods supply to the retailer can be formulated as follows: it is necessary to determine the range and volumes of supply of perishable goods that will maximize profits given the constraints of the funds available for their purchase, storage volumes and weight, as well as lost profits. This problem can be formalized in the form of the following model.

We need to determine the vector of range $Y^{*}=\left\{y_{1}^{*}, y_{2}^{*}, \ldots, y_{J}^{*}\right\}$ and the volumes of the next supply of perishable goods in a way that

$$
W\left(Y^{*}\right)=\sum_{j=1}^{J} W_{j}\left(T_{j}\right)=\max _{Y} W(Y)
$$

with the constraints

$$
\begin{gathered}
\sum_{j=1}^{J} y_{j} c_{0 j} \leq C_{0} \\
\hat{W}(Y) \leq \hat{W}^{*}(Y) \\
\sum_{j=1}^{J} y_{j} V_{j} \leq V^{*} \\
\sum_{j=1}^{J} y_{j} G_{j} \leq G^{*}
\end{gathered}
$$

where $\hat{W}^{*}(Y)$ is the acceptable amount of profit lost during the next supply of perishable goods in the range and volume determined by vector $\mathrm{Y}$.

Value $\hat{W}^{*}(Y)$ can be formed as a determined proportion of the value of supply of the goods, that is $\hat{W}^{*}(Y)=D C_{0}$.

Constraint (11) means that the value of the supplied batch of perishable goods must not exceed the amount of cash available for their wholesale purchase by the retailer. 
Constraint (12) means that the profit lost as a result of the defined range and volume of goods should not exceed the allowed value.

Constraint (13) means that the total supply of products must not exceed the warehouse capacity of the enterprise.

Constraint (14) means that the total weight of the supplied goods must not exceed the maximum weight of the stored goods allowed for the enterprise.

The methods for solving problems of type (10) - (14) depend on the properties of the supplied perishable goods. If these goods are divisible, then problem (10) - (14) belongs to the class of linear programming problems and can be solved, for example, using a simplex method $[14,15]$.

If the goods are unitary (indivisible), then problem (10) - (14) belongs to the class of linear integer programming problems. It can be solved, for example, by using a branch and bound method [16 - 21].

\section{Discussion}

The analysis has shown that a significant place in the supply chain belongs to the supply of perishable products, the demand for which is random. The rational management of such supply chains is not possible without the use of appropriate mathematical models to form management decisions. Such models should be based on stochastic and optimization approaches. At the same time, stochastic approaches are designed to match the volumes of supplied goods with the demand for them, and optimization approaches are designed to form an assortment and volumes of supplies that maximize the profits of participants in the supply chain with the existing restrictions on the possibilities of storage facilities for storing products, the availability of funds necessary to purchase their next batch and etc.

The model proposed in the article provides a combination of stochastic and optimization approaches in the interests of supply chain management for perishable products. Application of this model makes it possible to improve the efficiency of management of such supply chains.

\section{Conclusions}

In general, the proposed model (1) - (14) forms the basis of the methodological approach to defining a rational range and volume of perishable goods supplied to retailers, taking into account the stochastic nature of the demand for goods, limited shelf life, as well as the capacity of warehouses for storage of products and the availability of funds necessary for purchasing the next batch. If the model is used in practice, it can increase the management efficiency of supplies of perishable goods in supply chains functioning at the time of random demand.

\section{References}

1. I. Ilin, O. Voronova, T. Knykina, Proceedings of the 33rd International Business Information Management Association Conference, IBIMA 2019: Education Excellence and Innovation Management through Vision 2020, 5112-5121 (2019)

2. V. Orlova, I. Ilin, S. Shirokova, MATEC Web of Conferences 193 (2018)

3. S. Krasnov, S. Sergeev, A. Titov, E. Zotova, Modelling of digital communication surfaces for products and services promotion. IOP Conference Series: Materials Science and Engineering (2019) 
4. A. Chernysh, et al., E3S Web of Conferences 03003 (2018)

5. I.V. Ilin, Izotov, A.V., Shirokova, S.V., O.V., Rostova, A.I. Levina, Proceedings of 2017 20th IEEE International Conference on Soft Computing and Measurements 7970732, 812-814 (2017)

6. A. Lyovina, S. Kalyazina, M. Sinelnikov, A. Poljanskihh, Proceedings of the 33rd International Business Information Management Association Conference, IBIMA 2019: Education Excellence and Innovation Management through Vision 2020, 8728-8735 (2019)

7. Ilin, I.V., Bolobonov, D.D., Frolov, A.K. Proceedings of the 33rd International Business Information Management Association Conference, IBIMA 2019 Education Excellence and Innovation Management through Vision 2020, 5092-5102 (2019)

8. M.A. Sonkin, et al. J. Phys.: Conf. Ser. 803(1), 012006 (2017)

9. I. Bagaeva, et al., Proceedings of the E3S Web of Conferences 110, 02066 (2019)

10. A.F. Suprun et al., Automatic Control and Computer Sciences 52(8), 1105-1110 (2018)

11. A.I. Levina, A.S. Dubgorn, O.Y. Iliashenko, Proceedings - 2017 European Conference on Electrical Engineering and Computer Science, EECS 2017, 351-355 (2018) DOI: 10.1109/EECS.2017.72

12. E.S. Rodionova et al., International Journal of Supply Chain Management 8(1), 86-89 (2019).

13. S.M. Hannum, Potential impact of strawberries on human health: a review of the science. Nutritional Sciences (University of Illinois, USA, 2010)

14. G. Silkina, From analogue to digital tools of business control: Succession and transformation. IOP Conference Series: Materials Science and Engineering (2019)

15. A.O. Alekseyev, et al., Soviet Journal of Computer and Systems Sciences 5, 130 - 134 (1988)

16. M.A. Sonkin, et al., Proceedings of the 2016 Conference on Information Technologies in Science, Management, Social Sphere and Medicine ITSMSSM 2016 ACSR, 282-285 (2016)

17. V.G. Anisimov, Ye.G. Anisimov, USSR Computational Mathematics and Mathematical Physics 32(12), 1827-1832 (1992)

18. T. Saurenko, et al., Proceedings of the SHS Web of Conf. 44, 00009 (2018)

19. V.G. Anisimov, E.G. Anisimov, USSR Computational Mathematics and Mathematical Physics 37(1), 54-60 (1997)

20. A.O. Alekseyev, O.G. Alekseyev, V.G. Anisimov, E.G. Anisimov, USSR Computational Mathematics and Mathematical Physics 25(6), 50-54 (1985)

21. E.A. Zotova, et al., Proceedings of the Atlantis Highlights in Computer Sciences, volume 1. International Conference on Digital Transformation in Logistics and Infrastructure (ICDTLI 2019), 246-249 (2019) 